\title{
Incidence of hiatus hernia in asymptomatic subjects
}

\author{
N. H. DYER ${ }^{1}$ AND R. B. PRIDIE
}

From the London Hospital

The frequency with which hiatus hernias may be demonstrated during routine barium meals performed on patients complaining of gastrointestinal symptoms varies with the technique employed. Pridie (1966) examined 500 patients lying prone over a bolster and found hiatus hernias in $30 \%$. Since these patients were referred with symptoms suggestive of gastrointestinal disease, the significance of the hiatus hernia and its role in the production of symptoms could not be assessed. It was therefore decided to examine a series of asymptomatic patients and the findings are reported below.

\section{MATERIAL}

Ninety-five volunteers from the wards and out-patient clinic of a busy general medical firm were examined. They were referred over a six-month period with a wide range of medical conditions. Patients were selected only by the lack of symptoms suggestive of hiatus hernia and their willingness to undergo radiography; all had the nature of the experiment explained to them. Anyone who complained of epigastric pain, epigastric discomfort, heartburn, acid reflux, distension, dysphagia, vomiting, or substernal pain was excluded.

Although all the patients included initially claimed to be asymptomatic, some could be persuaded subsequently to admit to minor gastrointestinal symptoms and these were then recorded. Subjects suffering from chest pain were included provided that the pain was not related to food and had no other characteristics of oesophageal pain. This pain was analysed regardless of the presence or absence of minor abdominal symptoms. Dyspnoea was not investigated as objective evidence of the symptom was often lacking and associated diseases obscured its origin. Five groups of patients were therefore separated.

GROUP 1 No symptoms at any time (59 subjects).

GROUP 2 Minor gastrointestinal symptoms (36 subjects). Upper abdominal (24 subjects) The commonest symptom was flatulence, but non-specific fullness, nausea, and pain in the hypochondrium were also reported. Three patients who admitted to occasional mild heartburn unrelated to food or posture were included.

Lower abdominal (12 subjects) Diarrhoea, flatus, lower abdominal pain, and constipation were recorded.

${ }^{1}$ Now at St Bartholomew's Hospital, London.
GROUP 3 Chest pain (32 subjects).

Ischaemic heart disease (12 subjects) These patients all had an abnormal ECG tracing, and either complained of exertional chest pain or had suffered a proven cardiac infarct in the past, although they need not have suffered from chest pain subsequently.

Normal ECG (20 subjects) The pain had variable characteristics and was often attributed to musculoskeletal causes.

\section{METHOD}

Each patient first drank a glass of barium in order to reproduce the conditions of the previous study (Pridie, 1966), in which hiatus hernia was looked for at the end of a routine barium meal. He was then placed prone over a bolster and screened. The presence of barium in the oesophagus indicated free gastrooesophageal reflux. A further mouthful of barium was now swallowed and the bolus was watched as it passed down the oesophagus. A hiatus hernia was only diagnosed if it could be recorded on a film taken after a short delay, and if the mucosal folds in the hernial sac were continuous with those of the stomach (Fig. 1). Care was taken to differentiate between a hernia and a phrenic ampulla. An ampulla was judged to be present when the sac emptied itself completely in the recumbent position, and the oesophageal peristaltic wave could be seen to pass right through the sac. Only one film was taken and the screening time was kept to a minimum.

Measurements of the height and width of the supradiaphragmatic hernial sac were taken from the radiographic film, and the two-dimensional surface area was calculated. The figures do not represent the maximal distended sizes of the hernias, as the films were all taken after a short delay to allow some emptying. Magnification and other factors causing distortion were the same for all films in this and the previous series, which are therefore comparable.

\section{RESULTS}

Of the 95 people examined, 31 showed a hiatus hernia (Table I). This is an incidence of $33 \%$. The hernias were all bell-shaped and were of the 'sliding' variety (Fig. 1).

REFLUX This was demonstrated in five cases, ie, $16 \%$ of those with hernia. Reflux was not demonstrated in any subject in the absence of a hernia. 
TABLE I

INCIDENCE OF HIATUS HERNIA RELATED TO AGE AND SEX

Age Female

Male and Female

Percentage

\begin{tabular}{lrr}
\hline Under 30 & 16 & 4 \\
$30-39$ & 7 & 3 \\
$40-49$ & 16 & 6 \\
$50-59$ & 13 & 3 \\
$60-69$ & 5 & 2 \\
$70-79$ & 4 & 2 \\
Total & 61 & 20
\end{tabular}

\begin{tabular}{rr} 
Total Hernia \\
\hline 4 & \\
4 & \\
8 & \\
9 & \\
6 & \\
3 & \\
34 &
\end{tabular}

SIZE The hernias were small or medium-sized (Table II). The table also shows that there was no difference in the sizes of the hernias in this series when compared with the first 31 consecutive hernias of our previous series.

\section{TABLE II}

SIZE OF THE HIATUS HERNIAS

\begin{tabular}{|c|c|c|}
\hline $\operatorname{Size}^{1}(\mathrm{sq} \mathrm{cm})$ & Present Series & Pridie $(1966)^{2}$ \\
\hline Under 10 & 9 & 9 \\
\hline $10-20$ & 15 & 15 \\
\hline $20-30$ & 6 & 5 \\
\hline over 30 & 1 & 2 \\
\hline Total & 31 & 31 \\
\hline
\end{tabular}

${ }^{1}$ The films were all taken at a time when the hiatus hernia had partially emptied.

${ }^{2}$ See text.

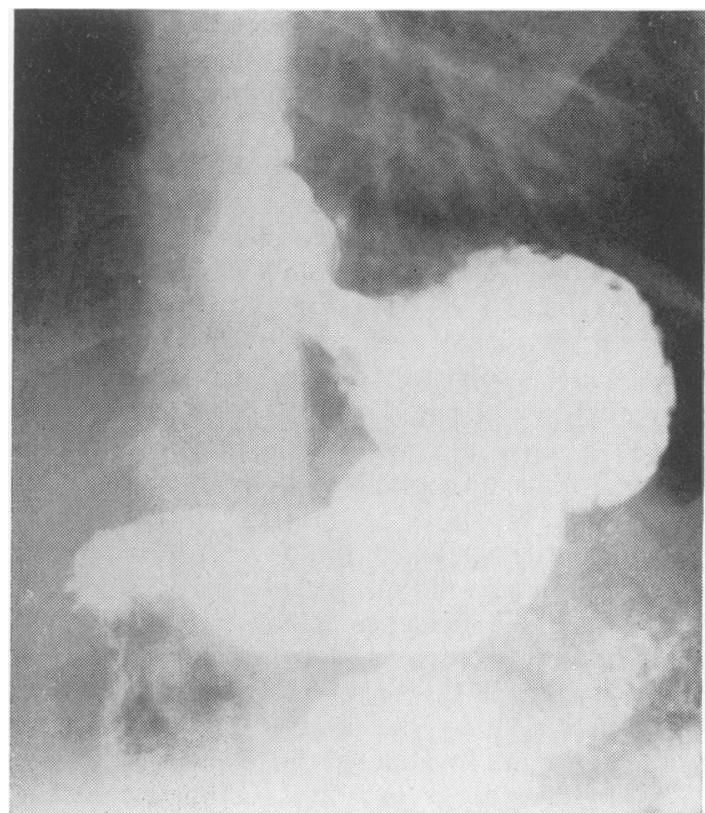

FIG. 1. Radiograph showing a hiatus hernia representative of the series.
AGE The incidence of hernia in each decade is shown in Table I. Thirty per cent of the patients who were under the age of $\mathbf{3 0}$ had hiatus hernia, which is similar to the incidence in the whole series. Moreover, there was no tendency for the incidence to increase with advancing age.

SEX Nearly twice as many men as women were included in the study by chance, but the overall incidence of hernia in each sex was similar $-33 \%$ in men, $32 \%$ in women. Table I shows the frequency of hernia in each sex and for each decade. Although the numbers are small, there is no apparent correlation.

OBESITY As a rough guide to obesity, an index was calculated by dividing the weight of each patient by his height. In Table III the material has been arbitrarily separated into three groups on the basis of this ratio. Although there were fewer hernias among the lighter (low ratio) patients, the incidence did not rise progressively with weight. In fact, in the seven patients with the highest ratios $(2 \cdot 7$ to 3.0$)$, there was only one hernia.

\section{TABLE III}

RELATION OF HIATUS HERNIA TO WEIGHT AND HEIGHT

Weight-height Ratio Total No 1 Hernia Hernia Percentage (lbs/in.)

\begin{tabular}{cccc} 
Total No. & $\begin{array}{c}\text { Hernia } \\
\text { Absent }\end{array}$ & $\begin{array}{c}\text { Hernia } \\
\text { Present }\end{array}$ & Percentage \\
\hline 21 & 17 & 4 & 19 \\
51 & 31 & 20 & 39 \\
19 & 13 & 6 & 32 \\
91 & 61 & 30 & 33
\end{tabular}

${ }^{1}$ Four patients excluded because of incomplete data. Only one of these showed a hernia.

MINOR SYMPTOMS These symptoms were not related to the presence of a hernia (Table IV). Moreover, it was not possible to demonstrate an association of any particular symptom with hiatus hernia. Flatulence was reported by 11 patients, of whom four had a hernia. Three patients with occasional heartburn were included, of whom one had a hernia. 
TABLE IV

ASSOCIATION OF MINOR ABDOMINAL SYMPTOMS AND HIATUS HERNIA

\begin{tabular}{lcccc} 
& Total & $\begin{array}{c}\text { Hernia } \\
\text { Absent }\end{array}$ & $\begin{array}{c}\text { Hernia } \\
\text { Present }\end{array}$ & Percentage \\
\hline None & 59 & 41 & 18 & $30 \cdot 5$ \\
Upper & 24 & 17 & 7 & 29 \\
Lower & 12 & 6 & 6 & 50
\end{tabular}

CHEST PAIN From Table $\mathrm{V}$ it appears that hiatus hernia may be associated with ischaemic heart disease. However, the results are not significant when compared with the group complaining of other chest pains or the whole series ( $P>0.7$ using the $\chi^{2}$ test). The incidence of hernia in the presence of other chest pains is not increased.

\section{TABLE V}

ASSOCIATION OF CHEST PAIN AND HIATUS HERNIA

$\begin{array}{ccc}\text { Total Hernia } & \begin{array}{l}\text { Hernia } \\ \text { Present }\end{array} & \text { Percentage } \\ & & \end{array}$

\section{Ischaemic}

heart disease 12

Normal ECG 20

6
13

6

50

13

\section{DISCUSSION}

The clinical diagnosis of hiatus hernia should be confirmed by radiography. Over the past 20 years, radiological techniques have been developed which have progressively increased the stress on the hiatus and yielded increasing numbers of hiatus hernias. The early studies of asymptomatic patients reported an incidence of hiatus hernia of less than $1.5 \%$ (St. John, Swenson, and Harvey, 1944; Brick and Amory, 1950; Cernock, 1953), and so it has been concluded that when hernias are demonstrated they are an important cause of symptoms. The present study is at variance with these earlier reports, and the high incidence of hernia is probably due to the more vigorous radiological technique employed, which never fails to demonstrate a hernia when compared with other methods (Sim, 1964).

The method of examination may bear little relation to the circumstances in the subject's daily life. However, bending and straining can cause an increased pressure gradient between abdomen and thorax (Marchand, 1955; Atkinson, Bottrill, Edwards, Mitchell, Peet, and Williams, 1961). Thus a loculus could appear during similar daily activities, but nevertheless may be asymptomatic and of no clinical significance.

The majority of studies on the incidence of hiatus hernia have been performed on subjects with gastro- intestinal symptoms, in whom the reported incidence has varied from 1 to $100 \%$. The radiological criteria of hiatus hernia have been discussed by Pridie (1966). The gross variation in incidence is often the result of employing different techniques, but some authors have included phrenic ampullae as well as hernias in their series (Vestby and Aakhus, 1966). The differentiation of these two conditions is important, as it is probable that a phrenic ampulla can be demonstrated in any subject when a careful examination is performed. Since the main conclusion that may be drawn from a survey of the literature is that the presence of a hiatus hernia bears an irregular relationship to the incidence of upper gastrointestinal symptoms, the correlation of symptoms with other radiological findings should be investigated. It has been shown that the size of the loculus is not related to symptoms (Hiebert and Belsey, 1961; Rex, Andersen, Bartholomew, and Cain, 1961) and this is also suggested by Table II. The demonstration of reflux may have more clinical significance, since it was shown more than twice as frequently in our symptomatic patients (Pridie, 1966) than in our asymptomatic patients. Unfortunately, a suspension of barium is more viscous than gastric juice and reflux may be demonstrated by $p \mathrm{H}$ measurements in the lower oesophagus in subjects who show no radiological reflux (Hill, Chapman, and Morgan, 1961).

Bockus (1963) states that 'everyone agrees that the incidence of hiatus hernia increases with age', and most authors report that the incidence rises sharply after the age of 50 . It is therefore interesting that there was no association with increasing age in this study, which is in contrast to our previous report (Pridie, 1966). This increased incidence in older age groups has been recorded in symptomatic subjects, and by excluding such cases the excess incidence may have been reduced in this series. However, it would seem that in asymptomatic subjects the oesophageal hiatus does not progressively weaken with age. The high incidence in young subjects is especially noteworthy and is more in keeping with a physiological rather than a pathological state.

There is little agreement on the sex ratio in hiatus hernia, although recent surveys have shown a slightly increased incidence in women. Pridie (1966) found hernias were almost twice as common in women as men. In this series, however, the sex ratio was equal, and so the excess number of men examined has not invalidated the results.

The high incidence of hiatus hernia cannot be explained by the inclusion of a disproportionate number of obese subjects. Although the weightheight ratio is a very crude index of body mass and 
obesity, it does show that there is no correlation between the presence of hernia and a high ratio. The undoubted association of obesity and hiatus hernia in many reports seems to apply only to symptomatic hernias.

From the results reported here it can be seen that hiatus hernia may be fortuitously associated with many pathological conditions, and it is likely that a survey of any disease by this particular radiological technique would reveal a hernia in about one-third of the cases. Such figures would be especially liable to provoke comment if the patients were young. The incidence of hiatus hernia in bronchial asthma has been reported as $34 \%$ by Clémençon, Ihre, and Plengiér (1960) using a technique similar to ours. These authors found that hernias were more frequent in moderate or severe asthmatics when compared with those suffering from mild disease, but the difference, although impressive, is only significant at the 0.1 level using the $\chi^{2}$ test. Nuzum (1952) found hernias in $25 \%$ of patients with angina of effort compared with only $12 \%$ in control subjects. However, the significance of this finding is obscured by the fact that the subjects were examined by a technique which does not stress the hiatus maximally and gives results which vary in their reproducibility. In this series, hernias were found in six out of 12 cases of ischaemic heart disease and in all four cases of asthma, but the numbers are too small to confirm any association.

Although hospital patients form a highly selected group, they illustrate the clinical problem of interpretation of hiatus hernia, since only hospital patients will have a barium meal performed. The incidence of hernia reported here is of the same order as in the previous study (Pridie, 1966) performed on patients with gastroduodenal symptoms. The hernias in both series were of comparable size and shape (Table II), but reflux was less common in the present series. Inadequate history taking was not responsible for the high incidence of asymptomatic hernias, since although 36 subjects admitted to some symptoms on questioning, these again could not be related to the presence of a hernia. A variable proportion of subjects with proven hernias lose their symptoms when followed up (Rex et al, 1961), and it is possible that a few of our patients were symptomatic in the past but have forgotten about this with the passage of time. The results suggest that an intrathoracic loculus demonstrated by this particular technique may have no clinical significance and that some modern techniques may therefore be inadequate on their own for the evaluation of hiatus hernia and may even obscure the diagnosis in conditions such as psychogenic dyspepsia.

\section{SUMMARY}

Ninety-five hospital patients with no appreciable gastrointestinal symptoms were examined by barium swallow while lying prone over a bolster. Small sliding hiatus hernias were present in $33 \%$. Reflux was demonstrated in five. This high incidence was not related to age, sex, or weight. When such hernias are demonstrated in clinical practice, they should not be accorded clinical significance unless the symptoms strongly suggest hiatus hernia.

We would like to thank Dr K. M. A. Perry and Dr D. W. Vere for permission to examine their patients; Dr A. M. Dawson for helpful criticism of the manuscript; and Miss A. Lawrence for secretarial assistance.

\section{REFERENCES}

Atkinson, M., Bottrill, M. B., Edwards, A. T., Mitchell, W. M., Peet, B. G., and Williams, R. E. (1961). Mucosal tears at the oesophagogastric junction (the Mallory-Weiss syndrome). Gut, 2, 1-11.

Bockus, H. L. (1963). Gastroenterology, 2nd ed., vol. I, p. 239. Saunders, Philadelphia and London.

Brick, I. B., and Amory, H. I. (1950). Incidence of hiatus hernia in patients without symptoms. Arch. Surg., 60, 1045-1050.

Cernock, W. F. (1953). Incidence of asymptomatic hiatus hernia. Amer. J. dig. Dis., 20, 123.

Clémençon, G. H., Ihre, B. J. E., and Plengiér, L. H. (1960). Hiatal hernia in bronchial asthma. Gastroenterologia (Basel), 93, 337-356.

Hiebert, C. A., and Belsey, R. (1961). Incompetency of the gastric cardia without radiologic evidence of hiatal hernia. J. thorac. cardiovasc. Surg., 42, 352-262.

Hill, L. D., Chapman, K. W., and Morgan. E. H. (1961). Objective evaluation of surgery for hiatus hernia and esophagitis. Ibid., 41, 60-74.

Marchand, P. (1955). The gastro-oesophageal 'sphincter' and the mechanism of regurgitation. Brit. J. Surg., 42, 504-513.

Nuzum, F. R. (1952). Relationship of esophageal hiatus hernia to angina pectoris. J. Amer. med. Ass., 148, 1174-1177.

Pridie, R. B. (1966). Incidence and coincidence of hiatus hernia. Gut, 7, 188-189.

Rex, J. C., Andersen, H. A., Bartholomew, L. G., and Cain, J. C. (1961). Esophageal hiatal hernia: a 10-year study of medically treated cases. J. Amer. med. Ass., 178, 271-274.

St. John, F. B., Swenson, P. C., and Harvey, H. D. (1944). An experiment in the early diagnosis of gastric carcinoma. Ann. Surg., $119,225-231$.

Sim, G. P. G. (1964). An evaluation of tests for hiatus hernia. Brit. J. Radiol., 37, 781-787.

Vestby, G. W., and Aakhus, T. (1966). Incidence of sliding hiatus hernia. Invest. Radiol., 1, 379-385. 